\title{
EXPERIMENTAL INVESTIGATION INTO FLOW IN AN EJECTOR WITH FOUR SYNTHETIC JETS
}

\author{
Václav DVOŘÁK', Petra DANČOVÁ, Petr ŠVARC
}

\begin{abstract}
The article deals with experimental investigation into flow in an ejector with four synthetic jets. The aim of the synthetic jets is to excite the mixing layer in the ejector and intensify the mixing process. The cavities of the synthetic jet actuators are hidden in the mixing chamber wall and the synthetic jets are perpendicular to the ejector axis. CTA and pneumatic measuring method were used to investigate the influences of synthetic jets on flow inside the ejector.
\end{abstract}

\section{INTRODUCTION}

The article deals with experimental investigation of mixing in axi-symmetric subsonic ejector with included devices generating synthetic jets. The aim of synthetic jets is to intensify the mixing process. The mixing can by intensified by many ways that can be divided into two groups, passive and active, as they were in publication by authors Ginevsky, Vlasov and Karavosov [1]. Shaping of the primary nozzle trailing edge belongs to the passive methods, generating of flow pulsation is an active method. The work [1] deals with free streams from jets, number of works dealing with active or passive control of mixing in ejectors are quite limited. E.g. Havelka et al. in experimental work [2] used a device inserted into the primary nozzle to add a tangential velocity component into the primary stream. Measuring showed that the secondary mass flow rate is increased for certain range of tangential velocity and the shorter mixing chamber is satisfactory. Waitz et al. investigated intensification of mixing with the help of a lobe nozzle in work [3]. Dvořák [4] optimized the lobe nozzle for mixing and found out that a nozzle with low number of big lobes is advantageous for high efficiency of the ejector. Chang and Chen [5] used a petal nozzle in a supersonic ejector and compared it with common diverging nozzle. They showed that the ejector with petal nozzle is better for higher area ratio $A_{3} / A_{1 k r} \geq 150$ than the ejector with common nozzle.

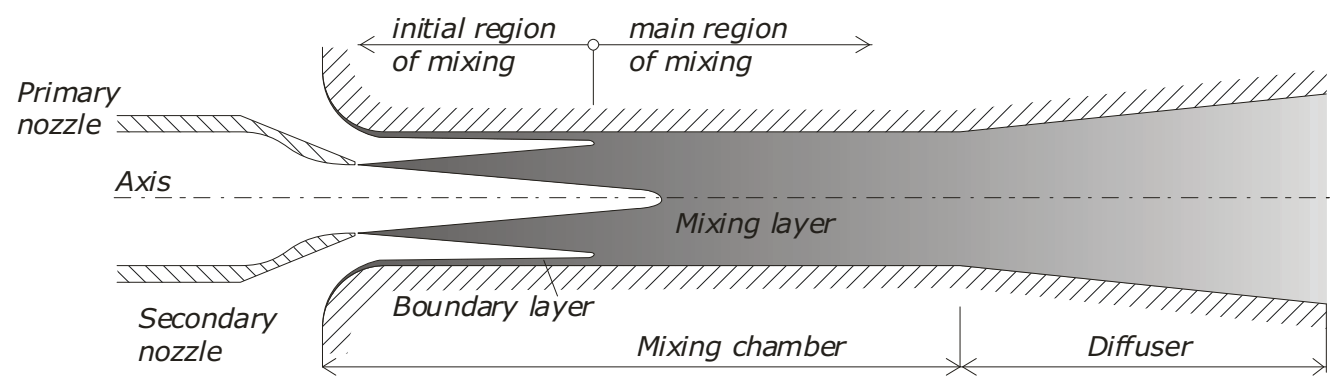

Figure 1: Schema of mixing processes in an ejector.

The aim of this study is to determine the influences of synthetic jets (SJs), which are perpendicular to the ejector axis, on the mixing and on ejector's operation. The

\footnotetext{
- Ing. Václav Dvořák, Ph.D., Studentská 2, 461 17, Liberec, Czech Republic, vaclav.dvorak@tul.cz Ing. Petra Dančová, Studentská 2, 461 17, Liberec, Czech Republic, petra.dancova@tul.cz Ing. Per Švarc, Studentská 2, 461 17, Liberec, Czech Republic, petr.svarc@tul.cz
}

This is an Open Access article distributed under the terms of the Creative Commons Attribution License 2.0, which permits unrestricted use, distribution, and reproduction in any medium, provided the original work is properly cited. 
presumption is that the SJs will intensify the mixing processes and thus will allow using of a shorter mixing chamber. In that case, friction losses decrease and the ejector efficiency increases.

Tylor and Williamson [6] divided the mixing into two regions, as we can see in Figure 1. In the initial region of mixing, the shear layer between the primary and the secondary stream does not reach the mixing chamber wall or the boundary layer. In the main region of mixing, the shear layer spreads across the whole mixing chamber cross section. The momentum decay is slow in the initial region and static pressure changes only slightly. We can consider a free stream here. But the momentum decay and also static pressure rise are accelerated in the main region. Optimizations made by Dvoŕák in work [7] showed that only choosing the velocity ratio $\omega=c_{2} / c_{1} \approx 0.3$ can lead to the high efficiency of the ejector. Unfortunately, the length of the initial region of mixing is than relatively long $\left(L_{0} \approx 3 D\right)$ in this case and causes high friction losses. The length of the main region depends less on the velocity ration. It is obvious that it is necessary to situate the SJs as close to the trailing edge of the primary nozzle as possible to intensify and accelerate the mixing processes.

The former work by authors Dvořák and Dančová [8] dealt with an ejector with only one synthetic jet. The purpose of that work was to investigate the possibility of using a synthetic jet to accelerate the mixing processes by the intensification of momentum and mass transfer, as it was shown by Trávníček and Vít in work [9].

In work [8], it was proved, that the influences of the operating SJ on the flow in the ejector were follows: The SJ accelerated the mixing process only negligibly, but for the regimes with high ejection ratio, the SJ stabilizes the flow fluctuations in the diffuser and thus the higher back pressure and higher efficiency are achieved. The SJ placed in the beginning of the mixing chamber influenced the flow in the diffuser positively, but when placed at the end of the mixing chamber, the improvements were reduced. Velocities of the primary stream in the centre of the mixing chamber were affected during the operation of the SJ, but the secondary stream and the mixing shear layer were affected only in the immediate vicinity of the SJ.

\section{EXPERIMENTAL RESEARCH}

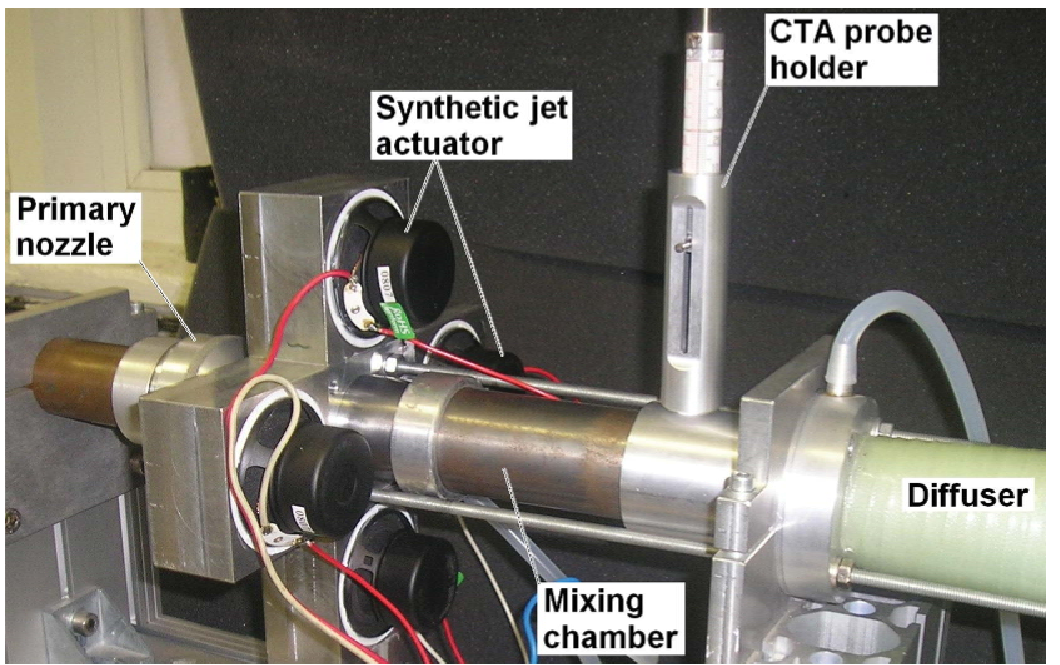

a)

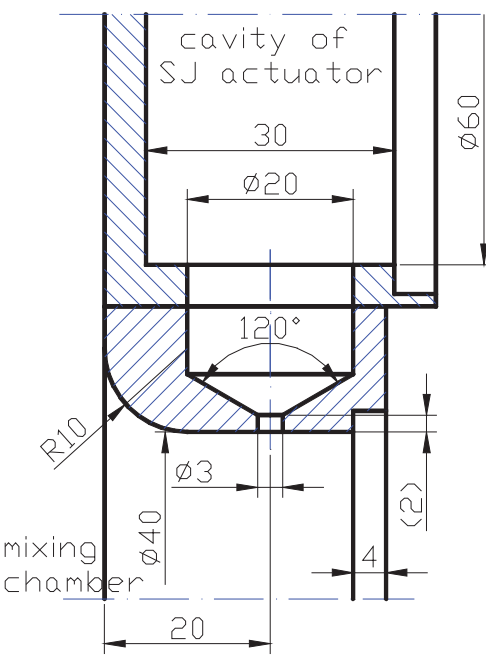

b)

Figure 2: System of the synthetic jet and the ejector, a) photo of measuring arrangement, b) dimensions of SJ actuators. 
A new design and experiments were suggested on the base of these results. In this work, we use four synthetic jets (SJs) with higher natural frequency. The SJs are placed just in the beginning of the mixing chamber. Dimensions of SJs and theirs position into the mixing chamber wall are obvious form Figure 2. The SJ actuators consist from sealed cavity and one loudspeaker (MONACOR SP-7/4S) with nominal parameters: $4 \Omega$, 5Wmax. These loudspeakers have the same power and diameters. Loudspeakers membranes have stiff cone shape and they can be considered pistons, which control the jet. Actuators were fed with sinusoidal signal with total electrical power $\mathrm{P}=1.1 \mathrm{~W}$. Signal was generated from Tektronix AFG 3102 signal generator and was amplified with Omnitronic MPZ-180 amplifier. The four actuators of SJ were connected up in anti-axisymmetrical mod, so each two opposite actuators worked together, while the other two were delayed by half period. The characteristic of the system of four synthetic jets were measured by Novotný, Vít and Vestfálová in work [10]. First step of HWA measurement was the determination of nominal frequency of the SJ - i.e. frequency on which the SJ actuators work with the highest power. Nominal frequency was found as $f=426 \mathrm{~Hz}$.

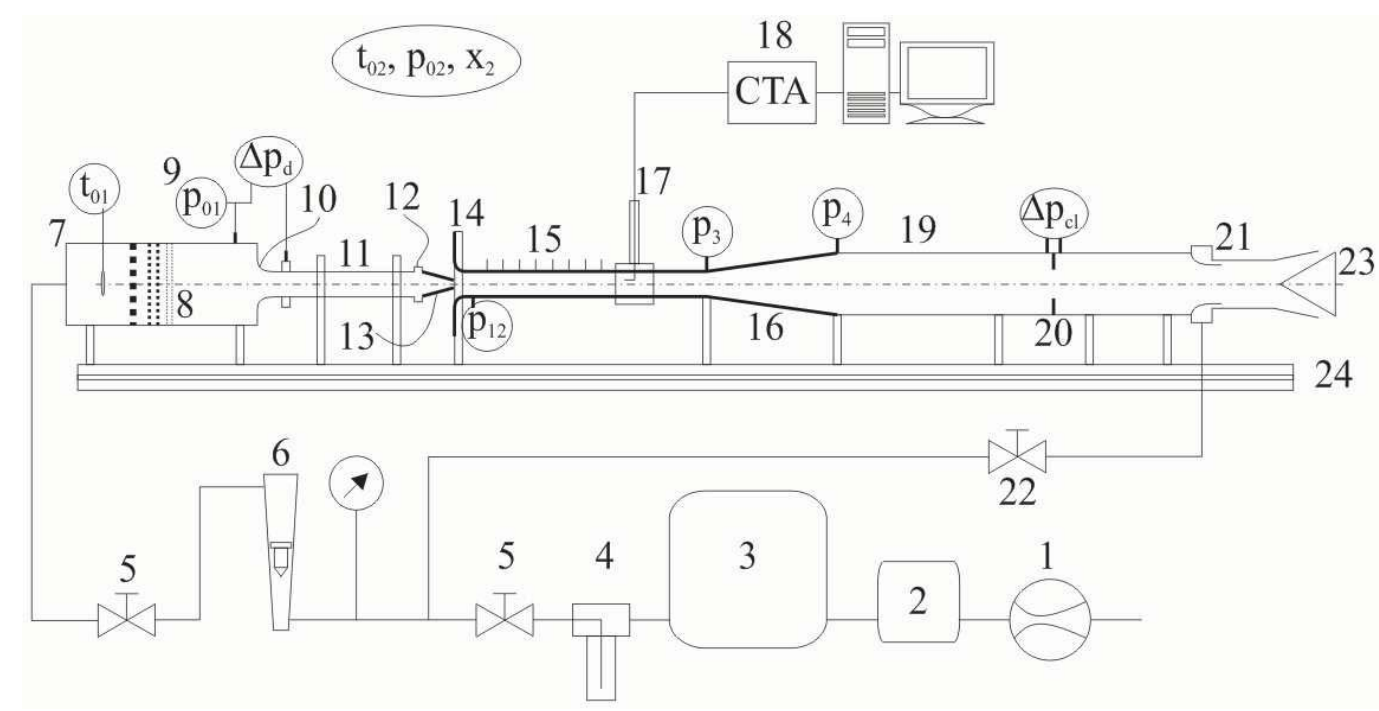

Figure 3: Experimental arrangement: 1 - compressor, 2 - air dryer, 3 - tank, 4 filter, 5 - reduction valve, 6 - rotameter, 7 - stilling chamber, 8 - stilling riddles, 9 - measuring of $p_{01}$ and $t_{01}, 10$ - measuring of primary mass flow rate, 11 primary tube, 12 - primary nozzle, 13 - secondary nozzle, 14 - mixing chamber, 15 - static pressure taps, 16 - diffuser, 17 - CTA probes, 18 - CTA measuring, 19 - measuring of back-pressure, 20 - measuring of total mass flow rate, 21 suction ejector, 22 - control valve, 23 - chocking, 24 - bed.

A circular converging nozzle with diameter $d=19.2 \mathrm{~mm}$ was used. The mixing chamber had diameter $D=40 \mathrm{~mm}$. The area ratio of nozzles was $\mu=A_{1} / A_{2}=0.3$ and the relative length of the mixing chamber was only $L / D=6$. A diffuser with $6^{\circ}$ enlargement and with outlet diameter $71.2 \mathrm{~mm}$ was placed behind the mixing chamber. A traversing device for CTA probes is obvious from Figure 2. CTA method was used to measure velocity and turbulence profiles inside the mixing chamber. In the present study, HWA system from DANTEC is used: anemometer Dantec Stream Line 90C10, A/D converter NI-PCI-MIO- 
$16 \mathrm{E}-1$, connector block NI-CA 1000, hot wire probe 55R11. Overheat ratio was set 0.80 . Software StreamWare version 3.01 is used for data analysis.

Experimental arrangement for investigation of mixing processes in ejectors is displayed in Figure 3. The primary air flows from compressor through air dryer, control valves and stilling chamber, which guarantees constant value of stagnation pressure. Measuring of primary mass flow rate is behind the stilling chamber. The secondary air is sucked in to the mixing chamber directly from the laboratory. A diffuser to obtain higher back pressure and a measuring orifice to measure total mass flow rate is placed behind the mixing chamber. Chocking placed in the end of tube is used for set-up of high back pressure and additional suction ejector is used for set-up of low or even negative back pressure.

\section{RESULTS AND DISSCUSSION}
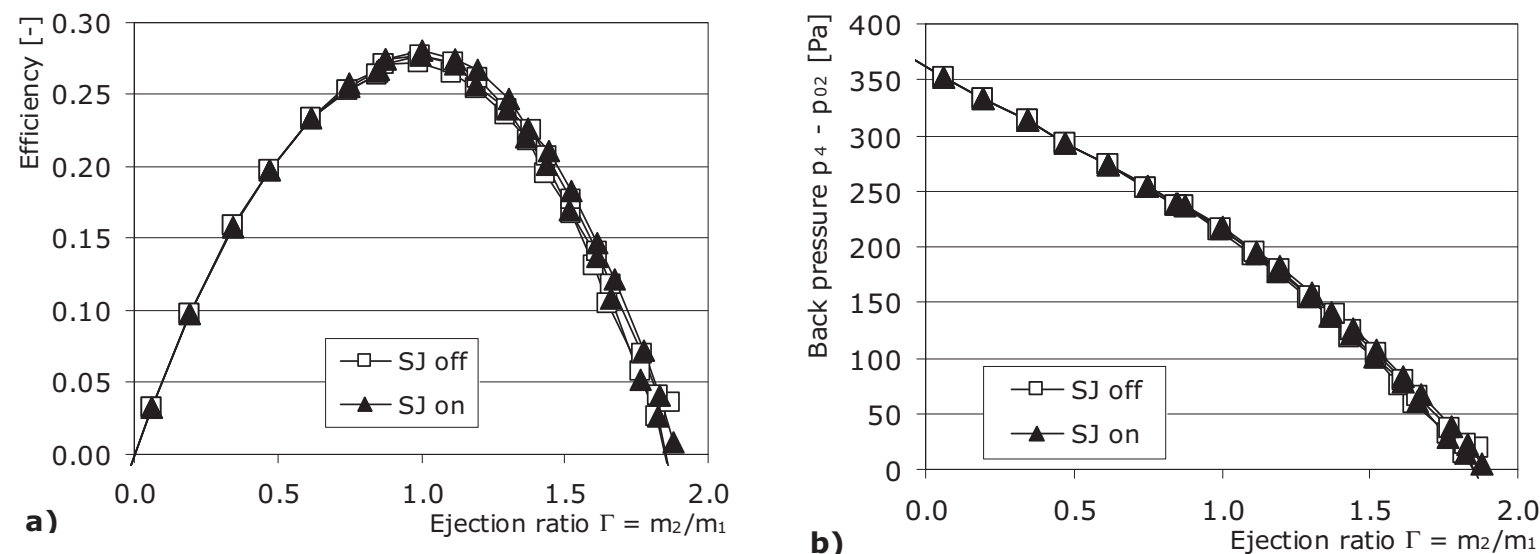

Figure 4: Measured curves of ejector with the SJs switched off and on. a) efficiency curve, b) back pressure.
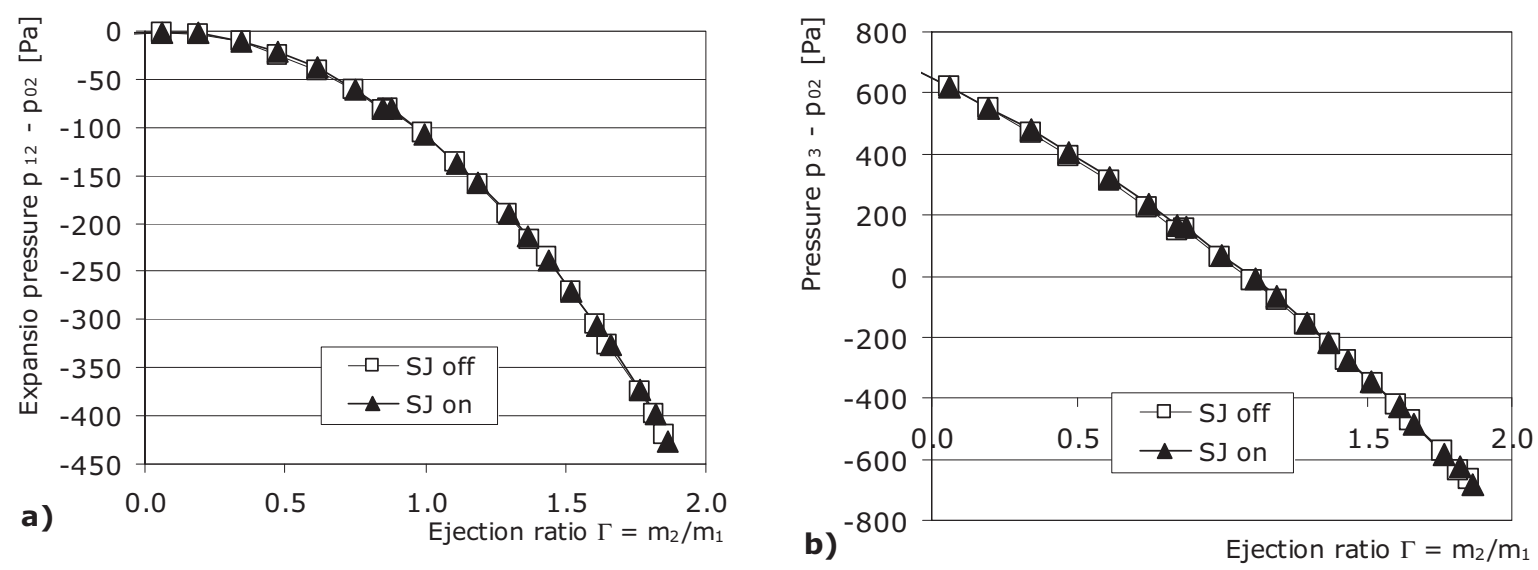

Figure 5: Measured curves of ejector with the SJs switched off and on. a) expansion pressure $\left.p_{12}, b\right)$ pressure $p_{3}$ at the end of the mixing chamber.

Results of measuring of efficiency of ejector with and without working synthetic jets are in Figure 4a. The same data are plotted into the diagram ejection ratio - back pressure in Figure $4 \mathrm{~b}$. It follows from the curves that the influence of the SJs on the flow in the ejector depends on the given ejection ratio. The ejection ratio is defined as the ratio of 
mass flow rates $\Gamma=\mathrm{m}_{2} / \mathrm{m}_{1}$. If the ejection ratio is high $\Gamma>1$, the SJs have a positive influence. For low ejection ratio $\Gamma<1$, the influence of the SJs is negligible. We can see on curves for ejector with the SJs switched off that variations of ejection ratio and back pressure occur for regimes of $\Gamma>1$. These random variations have character of low frequency, typically $\approx 0.1 \mathrm{~Hz}$. These variations are reduced and the back pressure is increased during operation of the SJs. It is confirmed that the SJs influence mostly regimes with high ejection ratio, i.e. with high velocity ratio, as it was proved in work [8]. But here, the improvements of ejector efficiency are not so high.

In work [8], it was found out that the SJ helped the ejector by improving the stability of flow in the diffuser. That was illustrated on curves of the expansion pressure $p_{12}$ and the static pressure $p_{3}$ at the end of the mixing chamber. Also for our case, both curves for the SJs switched off and on are displayed into only one curve, see Figure $5 \mathrm{a}$ and $5 \mathrm{~b}$. It means that the SJs do not influence these pressures.
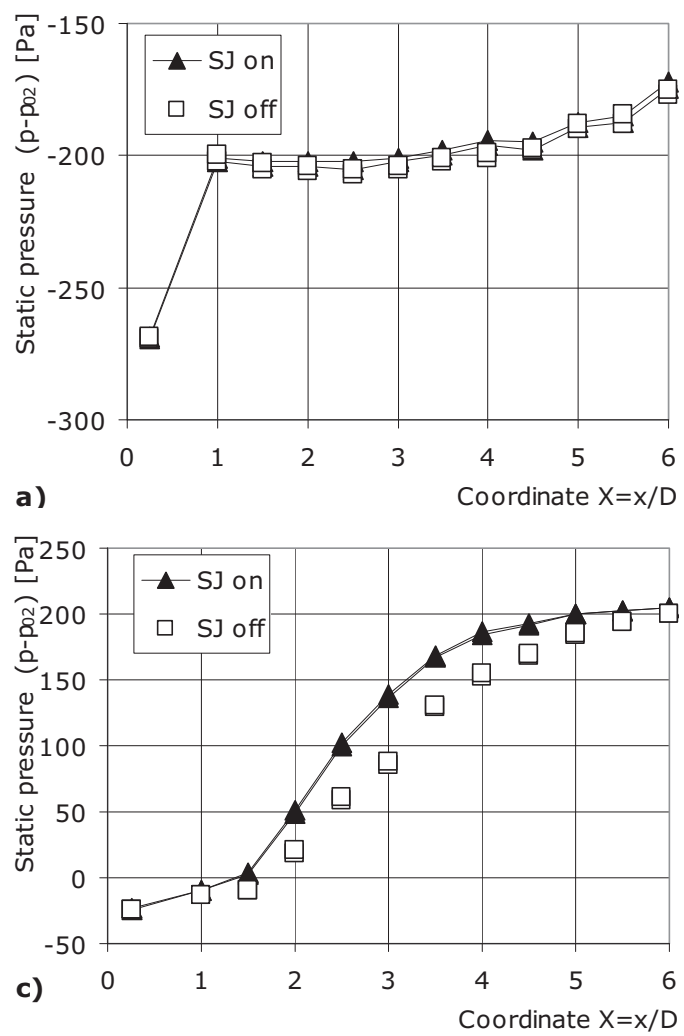

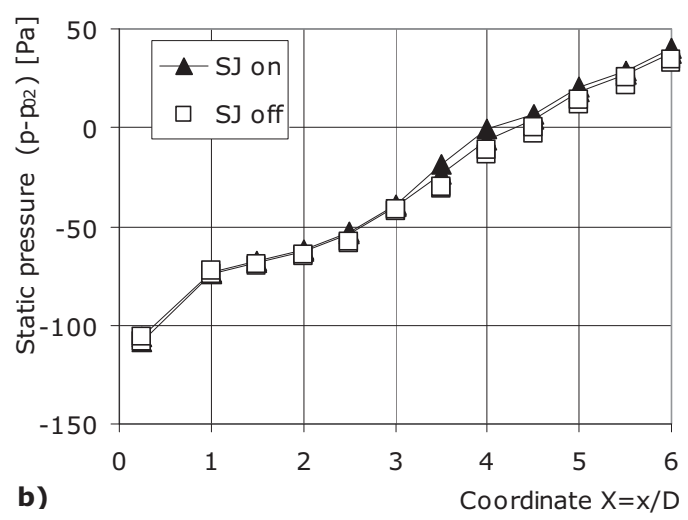

Figure 6: Static pressure distribution on the wall of the mixing chamber, with the SJ switched off and on.
a) $\Gamma=1.5, \omega=0.45$
b) $\Gamma=1.0, \omega=0.3$
c) $\Gamma=0.5, \omega=0.15$

To see how the SJs influence the mixing processes, we have to measure the static pressure distribution on the mixing chamber wall or velocity profiles across the mixing chamber. Curves of static pressure indicating the mixing are plotted in Figure 6. We can see that for low back pressure and so high ejection ratio $\Gamma$ and high velocity ratio $\omega=c_{2} / c_{1}$, the mixing processes are not affected by operation of SJs. But for the high back pressure and low velocity ratio, the mixing process is faster. We can observe from Figure $6 \mathrm{c}$, that the beginning of the main region of mixing, in which the static pressure is increasing rapidly, is moved upstream and the mixing is faster. Similar results were recorded in work [8] with only one SJ, but the accelerating of the mixing process was lower. The question is: Why SJs influence only regimes with low ejection and velocity 
ratios? To answer this question, we measured velocity profiles across the mixing chamber.
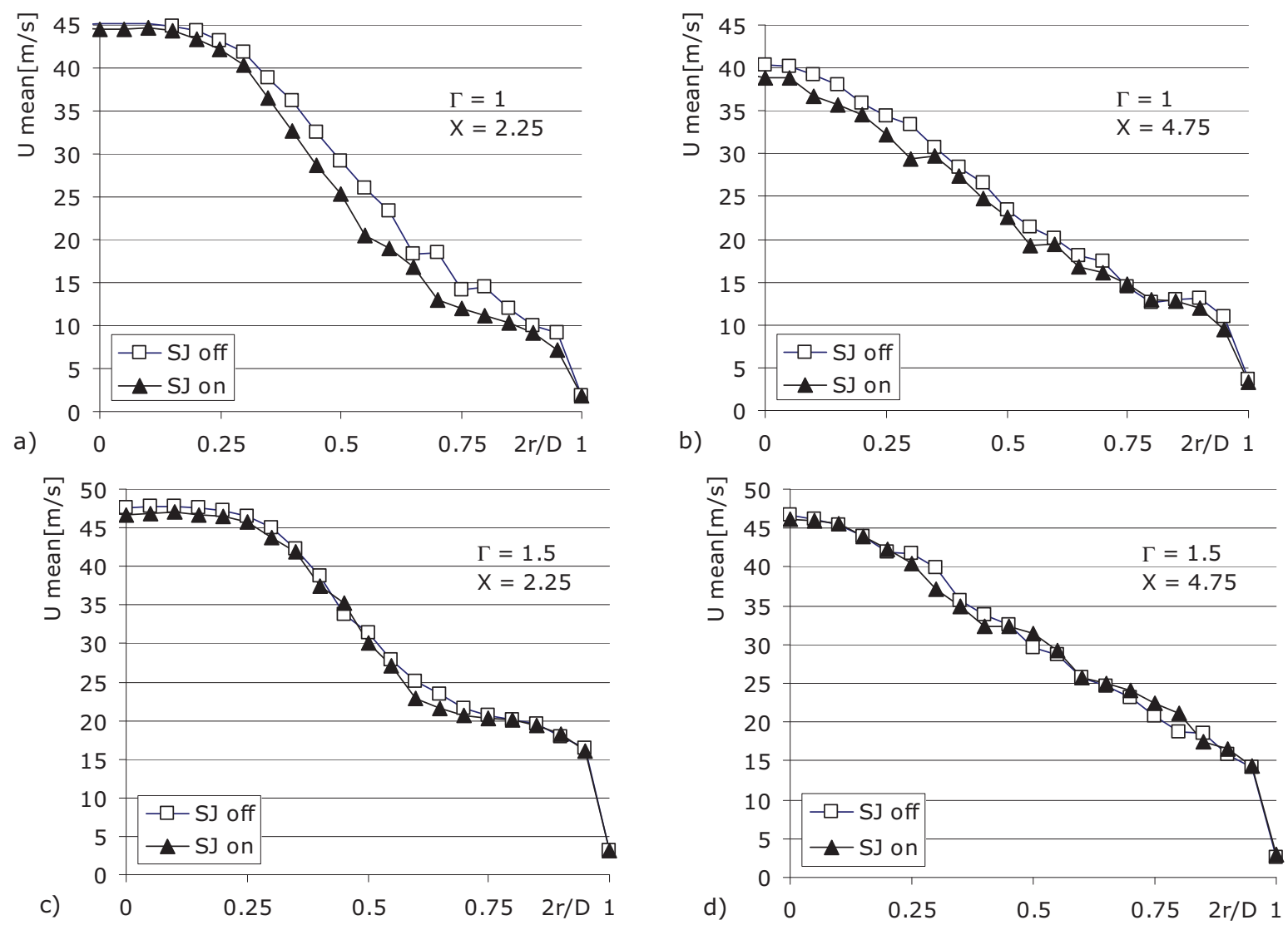

Figure 7: CTA measuring of mean velocity, a) and b) regime $\Gamma=1, c$ ) and d) regime $\Gamma=1.5, a)$ and $c) X=2.25(70 \mathrm{~mm}$ behind the $S J s), b)$ and d) 4.75 (170mm behind the SJs).

The measured velocity profiles inside the mixing chamber for regime with ejection ratio $\Gamma=1(\omega=0.3)$ are in Figure $7 \mathrm{a}$ and $7 \mathrm{~b}$. We can observe that the SJs influence the mixing processes only slightly. The differences between curves with SJs turned on and off are quite small compare to the differences obtained in work [8]. The effect of SJs becomes negligibly for very high ejection ratio as we can observe in Figure $7 c$ and $7 d$. To deeper understand the operation of SJs in the ejector, there are results of measuring of time dependency of mean velocity in Figure 8.

As we can see in Figure 8, the time dependency of the mean velocity is very low and virtually irrelevant. It seems that the system with four SJs do not work properly for high ejection ratio. The question is why four SJs with higher frequency are not better than only one SJ with lower frequency in [8]? As we mentioned before, the results with four SJs for low ejection ratio were even better than results of one SJ. For higher ejection and velocity ratios, the acceleration of mixing process becomes small and even negligible in some cases. Do we measure in a proper way? To disclose this puzzle, we have to take a look at Figure $5 \mathrm{a}$. As we can see, the difference of expansion pressure $\left(p_{12}-p_{02}\right)$, which is measured very close to the inlets of synthetic jet actuators, is negative. It allows the secondary stream to flow from the atmosphere to the mixing chamber. But it means that 
the loudspeaker, from which the SJ actuator is consisted from, works with a pressure difference equal to $\left(p_{12}-p_{a t m}\right)$ on its membrane, while $p_{102}=p_{a t m}$. Finally it seems that this had only marginal influence on the operation of loudspeakers used in work [8], but it is fatal for operation of nowadays used loudspeakers. This should be verified in next work.
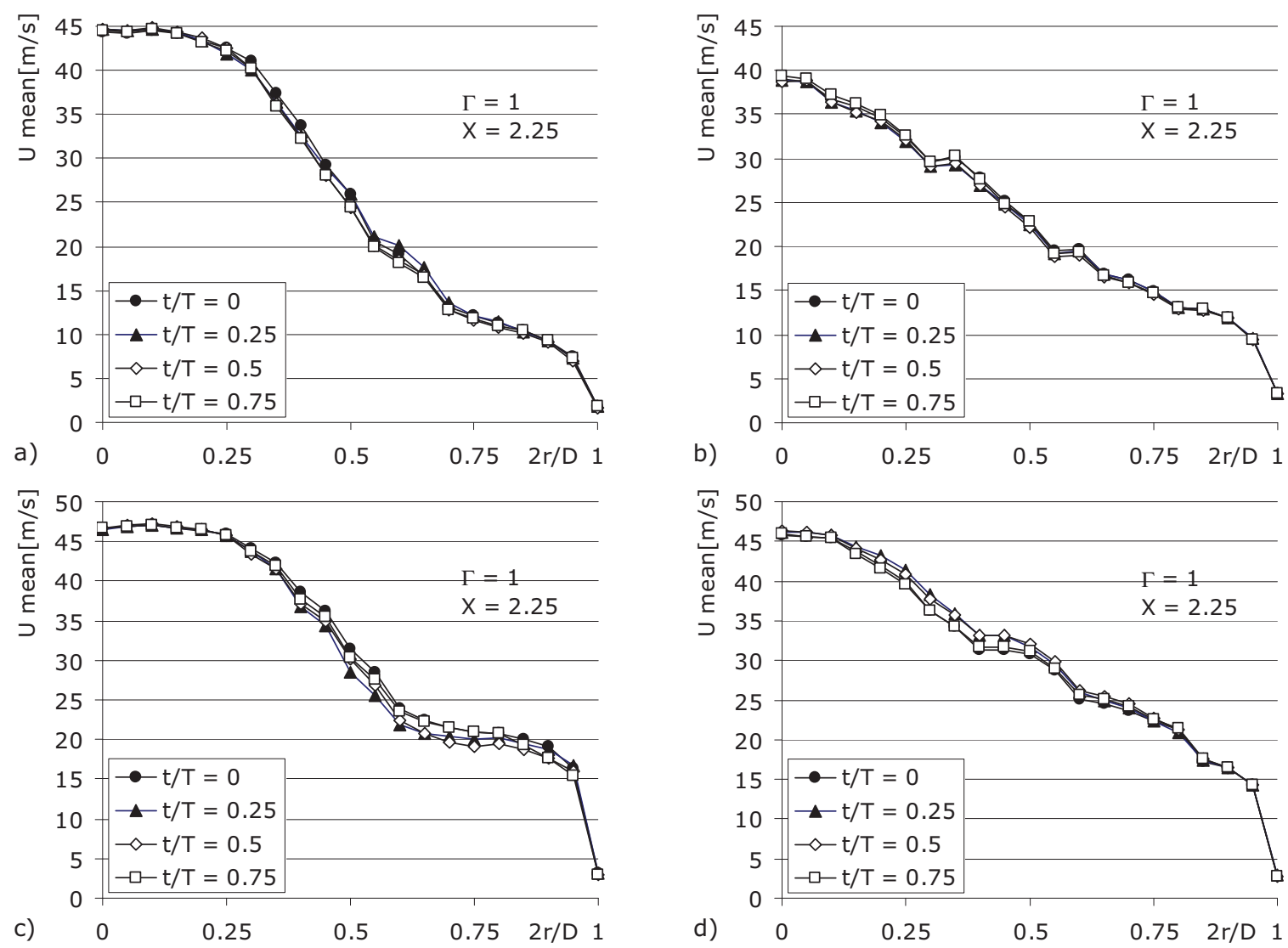

Figure 8: CTA measuring of time dependency of mean velocity, a) and b) regime $\Gamma=1, c)$ and $d)$ regime $\Gamma=1.5, a)$ and $c) X=2.25(70 \mathrm{~mm}$ behind the $S J), b)$ and d) 4.75 (170 $\mathrm{mm}$ behind the $\mathrm{SJ})$.

\section{Conclusions}

The curves of efficiency of the ejector with the system of four SJs switched on and off were measured. Static pressure distributions on the wall of the mixing chamber and velocity and turbulence profiles for chosen regimes were measured. The influences of the operating SJs on the flow in the ejector are follows: The SJs accelerates the mixing process only negligibly and only for low ejection and velocity ratios. For the regimes with high ejection ratio, the SJs stabilize the flow fluctuations in the diffuser and thus slightly higher back pressure and higher efficiency are achieved. The velocity profiles inside the mixing chamber are affected only negligibly for high ejection ratio.

It seems that the system of four SJs does not operate properly for higher ejection and velocity ratios. It is probably caused by pressure difference on loudspeakers membranes, which does not allow the SJ actuators to work properly. This idea should be verify in the 
next work. The system of the SJs should be improved to insure the same pressure on both sides of loudspeakers membranes.

\section{ACKNOWLEDGEMENTS}

This project was realized with financial support from the state resources by the Foundation of the Academy of Science of the Czech Republic, grant no. IAA200760801 and by the Czech Science Foundation, grant no. P101/10/1709.

\section{REFERENCES}

[1] Ginevsky A. S., Vlasov Y. V., Karavosov R. K.: Acoustic Control of Turbulent Jets. Springer-Verlag Berlin Heidelberg 2004, Germany.

[2] Havelka P., Linek V., Sinkule J., Zahradnik J., Fialova M.: Effect of the ejector configuration on the gas suction rate and gas hold-up in ejector loop reactors. Chemical Engineering Science, Vol. 52, No. 11, pp. 1701 - 1713, 1997.

[3] Waitz I. A., Qiu Y. J., Manning T. A., Fung A. K. S., Elliot J. K., Kerwin J. M., Krasnodebski J. K., O'Sullivan M. N., Tew D. E., Greitzer E. M., Marble F. E., Tan C. S. and Tillman II T. G.: Enhanced Mixing with Streamwise Vorticity. Proy. Aerospace Sci. Vol. 33, pp. 323-351, 1997.

[4] Dvořák V.: Study of optimization of lobed nozzle for mixing. Colloquium Fluid Dynamics, Institute of Thermomechanics AC CR, Prague, Czech Republic, pp 17$18,2007$.

[5] Yuan-Jen Chang, Yau-Ming Chen: Enhancement of a steam-jet refrigerator using a novel application of the petal nozzle. Experimental Thermal and Fluid Science 22 (2000) 203-211.

[6] Tyler, R. A., Williamson, R. G.: Confined mixing of coaxial flows. Aeronautical report LR-602, NRC no. 18831, Division of Mechanical Engineering, Ottawa, Canada 1980.

[7] Dvořák V.: Shape Optimization and Computational Analysis of Axisymmetric Ejector. 8th International Symposium on Experimental and Computational Aerothermodynamics of Internal Flows, July 2-5, 2007 - Ecole Centrale de Lyon, France, 2007, pp 273-278.

[8] Dvořák V., Dančová P.: Experimental Investigation into Flow in an Ejector with Perpendicular Synthetic Jet. In: Experimental Fluid Mechanics 2009, Liberec 25. - 27. November 2009. pp $44-51$.

[9] Trávníček Z., Vít T.: Hybrid synthetic jet intended for enhanced jet impingement heat/mass transfer. In.: Proc. 13th International Heat Transfer Conference IHTC-13, Sydney, NSW Australia 2006.

[10] Novotný P., Vít T., Vestfálová M.: Basic Characteristics of Array of Pulsatile jets. In: Experimental Fluid Mechanics 2010, Liberec 24. - 26. November 2010. 